\title{
Enantiomeric Resolution of $\alpha$-Amino Acid Derivatives on Two Diastereomeric Chiral Stationary Phases Based on Chiral Crown Ethers Incorporating Two Different Chiral Units
}

\author{
Hee Jin Kim, Hee Jung Choi, Yoon Jae Cho, and Myung Ho Hyun* \\ Department of Chemistry and Chemistry Institute for Functional Materials, Pusan National University, Pusan 609-735, \\ Korea. E-mail:mhhyun@pusan.ac.kr \\ Received March 31, 2010, Accepted April 15, 2010
}

\begin{abstract}
Two diastereomeric chiral stationary phases (CSPs) were applied to the liquid chromatographic resolution of various racemic $\alpha$-amino methyl esters, $\alpha$-amino $N, N$-diethylamides and $\alpha$-amino $N$-propylamides. The CSP incorporating $(R)$ 3,3'-diphenyl-1,1'-binaphtyl and $(R, R)$-tartaric acid unit as chiral barriers did not show any chiral recognition. In contrast, the CSP incorporating $(R)$-3,3'-diphenyl-1,1'-binaphtyl and $(S, S)$-tartaric acid unit as chiral barriers was found to show excellent chiral recognition especially for the two enantiomers of $\alpha$-amino $N$-propylamides. Some of $\alpha$-amino methyl esters and $\alpha$-amino $N, N$-diethylamides were also resolved on the CSP incorporating $(R)$-3,3'-diphenyl-1,1'binaphtyl and $(S, S)$-tartaric acid unit. From these results it was concluded that the two chiral units composing the diastereomeric CSPs can show "matched" or "mismatched" effect on the chiral recognition according to their absolute stereochemistry.
\end{abstract}

Key Words: Chiral stationary phase, Enantiomeric resolution, Liquid chromatography, $\alpha$-Amino acid derivatives

\section{Introduction}

Chiral crown ethers have been known to be very useful as chiral selectors of liquid chromatographic chiral stationary phases (CSPs) for the separation of the two enantiomers of racemic primary amino compounds. ${ }^{1}$ Especially two types of chiral crown ethers incorporating chiral 1,1'-binaphthyl unit or two tartaric acid units have been most successfully utilized. CSPs based on crown ethers incorporating chiral 1,1'-binaphthyl unit was first developed by Cram and coworkers in late 1970s, but the chiral recognition efficiency of the CSPs was not so effective. ${ }^{2}$ Afterwards, CSPs based on (3,3'-diphenyl-1,1'-binaphthyl)-20-crown-6 dynamically coated on octadecyl silica gel ${ }^{3}$ or covalently bonded to silica gel ${ }^{4}$ were developed and successfully applied to the resolution of racemic primary amino compounds.

CSPs based on a crown ether incorporating two tartaric acid units, (+)-(18-crown-6)-2,3,11,12-tetracarboxylic acid, which was first synthesized by Lehn and coworkers, ${ }^{5}$ were also very successful in the resolution of various racemic primary amino compounds ${ }^{6}$ or racemic non-primary amino compounds. ${ }^{7}$

However, chiral crown ethers incorporating both of 1,1'-binaphthyl unit and tartaric acid unit have never been known until we succeeded in the preparation of two diastereomeric chiral crown ethers, $(R, R, R)-\mathbf{1}$ and $(R, S, S)-\mathbf{1}$ (Figure 1), incorporating both of $(R)$-3,3'-diphenyl-1,1'-binaphthyl and $(R, R)$ - or $(S, S)$ tartaric acid unit. ${ }^{8}$ The two diastereomeric chiral crown ethers, $(R, R, R)-\mathbf{1}$ and $(R, S, S)-\mathbf{1}$, were tested for their possibility as chiral selectors of CSPs shortly ${ }^{8}$ and the two diastereomeric CSPs, $(R, R, R)$-CSP 2 and $(R, S, S)$-CSP 2 (Figure 1), which were prepared by bonding the two diastereomeric chiral crown ethers to silica gel, were found to show "matched" or "mismatched" effect on the chiral recognition for the two enantiomers of tocainide and its analogues according to their stereochemistry. ${ }^{9}$ In this study, as an another example, we wish to show that the two

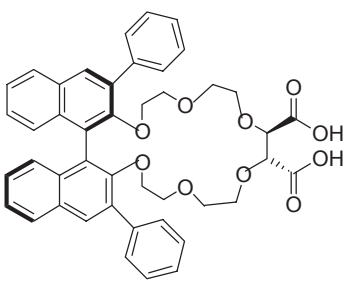

$(R, R, R)-1$

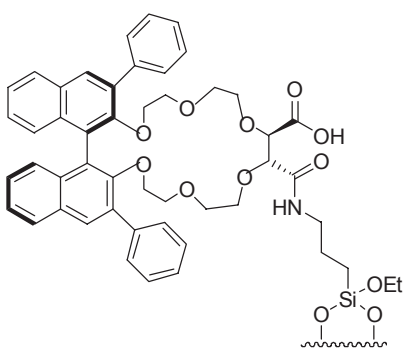

$(R, R, R)$-CSP 2

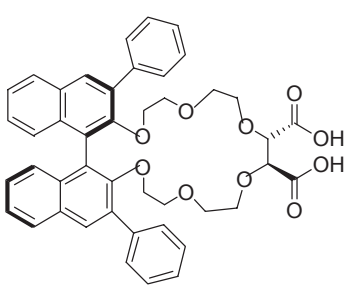

$(R, S, S)-1$

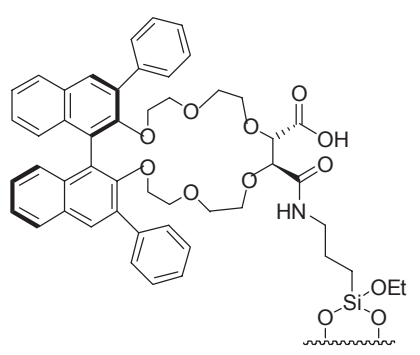

$(R, S, S)-C S P 2$
Figure 1. Structures of $(R, R, R)-\mathbf{1},(R, S, S)-\mathbf{1},(R, R, R)$-CSP 2 and $(R, S, S)$ CSP 2.

diastereomeric CSPs show distinct "matched" or "mismatched" effect on the chiral recognition for the two enantiomers of racemic $\alpha$-amino esters or $\alpha$-amino amides.

\section{Experimental}

Chromatography was performed with an HPLC system consisting of a Waters model 510 HPLC Pump (Milford, MA, USA), a Rheodyne model 7725i injector (Rohnert Park, CA, USA) with a $20 \mu \mathrm{L}$ sample loop, Waters 486 tunable absorbance 
detector (Milford, MA, USA) and Younglin Autochro data module (Software: YoungLin Autochro-WIN 2.0 plus) (Seoul, Korea). Chiral columns $(150 \times 4.6 \mathrm{~mm}$ I.D. $)$ packed with $(R, R$, $R)$-CSP 2 or $(R, S, S)$-CSP 2 were available from the previous study. ${ }^{9}$ The temperature of the chiral columns was maintained at $20{ }^{\circ} \mathrm{C}$ by using a Julabo F30 Ultratemp 2000 cooling circulator (Seelbach, Germany).

Racemic and optically active analytes including $\alpha$-amino esters and $\alpha$-amino amides (3) were prepared from corresponding $\alpha$-amino acids as following. Racemic or optically active $\alpha$-amino acids were treated with di-tert-butyldicarbonate in the presence of triethylamine in a mixed solvent of dioxane and water $(1: 1$, $\mathrm{v} / \mathrm{v})$ to afford $N$ - $t$-BOC- $\alpha$-amino acids. $N$ - $t$-BOC- $\alpha$-Amino acids thus prepared were treated with methanol, diethylamine or propylamine in the presence of coupling agent EEDQ (2-ethoxy-1ethoxycarbonyl-1,2-dihydroquinoline) in methylene chloride to afford $N$ - $t$-BOC- $\alpha$-amino esters or $N$ - $t$-BOC- $\alpha$-amino amides. Finally, treatment of $N$ - $t$-BOC- $\alpha$-amino esters or $N-t$-BOC- $\alpha-$ amino amides with trifluoroacetic acid in methylene chloride produced racemic and optically $\alpha$-amino esters and $\alpha$-amino amides (3).

Each of racemic and optically active $\alpha$-amino esters and $\alpha$ amino amides (3) thus prepared was dissolved in methanol (usually $1.0 \mathrm{mg} / \mathrm{mL})$ and then used for the resolution on $(R, R, R)$-CSP 2 and $(R, S, S)$-CSP 2 . The usual injection volume was $0.3 \mu \mathrm{L}$.
The void volume was determined by injecting 1,3,5-tri-tertbutylbenzene as an unretained analyte.

\section{Results and Discussion}

Resolution of primary amino compounds on chiral crown ether-based CSPs has been usually performed with the use of acidic aqueous mobile phase. ${ }^{4,6}$ However, tocainide and its analogues were previously found not to be resolved at all or to be resolved very poorly on $(R, R, R)$-CSP 2 and $(R, S, S)$-CSP 2 with the use of acidic aqueous mobile phase. ${ }^{9}$ Instead, a mixed solvent consisting of ethanol-hexane-trifluoroacetic acid-water (30:70:0.5: $0.2, \mathrm{v} / \mathrm{v} / \mathrm{v} / \mathrm{v}$ ) was found to be most useful as a mobile phase for the resolution of tocainide and its analogues on $(R, R, R)$-CSP 2 and $(R, S, S)$-CSP 2. ${ }^{9}$ Similarly, in this study, we found that racemic $\alpha$-amino esters and $\alpha$-amino amides (3) were not resolved on $(R, R, R)$-CSP 2 and $(R, S, S)$-CSP 2 with the use of acidic aqueous mobile phase, but they were resolved quite well with the use of a mixed solvent consisting of ethanol-hexane-trifluoroacetic acid-water (30:70:0.5:0.2, v/v/v/v) as a mobile phase especially on $(R, S, S)$-CSP 2.

The chromatographic results for the resolution of $\alpha$-amino esters and $\alpha$-amino amides (3) on $(R, R, R)$-CSP 2 and $(R, S, S)$ CSP 2 with the use of a mixed solvent consisting of ethanolhexane-trifluoroacetic acid-water (30:70:0.5:0.2, v/v/v/v) as a

Table 1. Resolution of $\alpha$-amino esters and $\alpha$-amino amides (3) on $(R, R, R)$-CSP 2 and $(R, S, S)$-CSP $\mathbf{2}^{a}$<smiles>[X]C(N)=O</smiles>

\begin{tabular}{|c|c|c|c|c|c|c|c|c|}
\hline \multirow{2}{*}{ entry } & \multicolumn{2}{|c|}{ Analytes (3) } & \multicolumn{3}{|c|}{$(R, R, R)$-CSP 2} & \multicolumn{3}{|c|}{$(R, S, S)-\mathrm{CSP} 2$} \\
\hline & $\mathrm{R}$ & $\mathrm{X}$ & $k_{1}$ & $\alpha$ & $\mathrm{R}_{\mathrm{S}}$ & $k_{1}$ & $\alpha$ & $\mathrm{R}_{\mathrm{S}}$ \\
\hline $3 \mathbf{a}$ & $\mathrm{CH}_{3}$ & $\mathrm{OCH}_{3}$ & 4.04 & 1.00 & - & $0.74(\mathrm{~S})$ & 1.57 & 3.22 \\
\hline $3 \mathbf{b}$ & (Alanine) & $\left(\mathrm{CH}_{3} \mathrm{CH}_{2}\right)_{2} \mathrm{~N}$ & 3.03 & 1.00 & - & $0.58(\mathrm{~S})$ & 1.33 & 2.45 \\
\hline $3 \mathrm{c}$ & & $\mathrm{CH}_{3} \mathrm{CH}_{2} \mathrm{CH}_{2} \mathrm{NH}$ & 2.47 & 1.00 & - & $0.42(\mathrm{~S})$ & 2.28 & 5.26 \\
\hline 3d & $\left(\mathrm{CH}_{3}\right)_{2} \mathrm{CH}$ & $\mathrm{OCH}_{3}$ & 3.60 & 1.00 & - & 0.67 & 1.00 & - \\
\hline $3 e$ & (Valine) & $\left(\mathrm{CH}_{3} \mathrm{CH}_{2}\right)_{2} \mathrm{~N}$ & 1.60 & 1.00 & - & 0.38 & 1.00 & - \\
\hline $3 f$ & & $\mathrm{CH}_{3} \mathrm{CH}_{2} \mathrm{CH}_{2} \mathrm{NH}$ & 1.35 & 1.00 & - & $0.27(\mathrm{~S})$ & 1.34 & 1.17 \\
\hline $3 g$ & $\left(\mathrm{CH}_{3}\right)_{2} \mathrm{CHCH}_{2}$ & $\mathrm{OCH}_{3}$ & 1.72 & 1.00 & - & $0.40(\mathrm{~S})$ & 1.23 & 1.25 \\
\hline $3 \mathrm{~h}$ & (Leucine) & $\left(\mathrm{CH}_{3} \mathrm{CH}_{2}\right)_{2} \mathrm{~N}$ & 1.27 & 1.00 & - & 0.35 & 1.00 & - \\
\hline $3 \mathbf{i}$ & & $\mathrm{CH}_{3} \mathrm{CH}_{2} \mathrm{CH}_{2} \mathrm{NH}$ & 1.10 & 1.00 & - & $0.25(\mathrm{~S})$ & 1.60 & 1.65 \\
\hline $3 \mathbf{j}$ & $\mathrm{CH}_{3} \mathrm{SCH}_{2} \mathrm{CH}_{2}$ & $\mathrm{OCH}_{3}$ & 3.65 & 1.00 & - & $0.64(\mathrm{~S})$ & 1.27 & 1.76 \\
\hline $3 \mathbf{k}$ & (Methionine) & $\left(\mathrm{CH}_{3} \mathrm{CH}_{2}\right)_{2} \mathrm{~N}$ & 2.37 & 1.00 & - & $0.50(\mathrm{~S})$ & 1.13 & 0.52 \\
\hline 31 & & $\mathrm{CH}_{3} \mathrm{CH}_{2} \mathrm{CH}_{2} \mathrm{NH}$ & 2.03 & 1.00 & - & $0.41(\mathrm{~S})$ & 1.74 & 2.60 \\
\hline $3 m$ & $\mathrm{C}_{6} \mathrm{H}_{5} \mathrm{CH}_{2}$ & $\mathrm{OCH}_{3}$ & 2.73 & 1.00 & - & $0.56(\mathrm{~S})$ & 1.08 & 0.32 \\
\hline $3 n$ & (Phenylalanine) & $\left(\mathrm{CH}_{3} \mathrm{CH}_{2}\right)_{2} \mathrm{~N}$ & 1.98 & 1.00 & - & 0.45 & 1.00 & - \\
\hline 30 & & $\mathrm{CH}_{3} \mathrm{CH}_{2} \mathrm{CH}_{2} \mathrm{NH}$ & 1.64 & 1.00 & - & $0.34(\mathrm{~S})$ & 1.34 & 1.81 \\
\hline $3 p$ & $\mathrm{C}_{6} \mathrm{H}_{5}$ & $\mathrm{OCH}_{3}$ & 2.55 & 1.00 & - & $0.58(\mathrm{~S})$ & 1.88 & 4.09 \\
\hline $3 q$ & (Phenylglycine) & $\left(\mathrm{CH}_{3} \mathrm{CH}_{2}\right)_{2} \mathrm{~N}$ & 1.78 & 1.00 & - & $0.45(\mathrm{~S})$ & 1.81 & 2.88 \\
\hline $3 r$ & & $\mathrm{CH}_{3} \mathrm{CH}_{2} \mathrm{CH}_{2} \mathrm{NH}$ & 1.51 & 1.00 & - & $0.41(\mathrm{~S})$ & 3.34 & 6.28 \\
\hline
\end{tabular}

${ }^{a}$ Mobile phase: ethanol-hexane-trifluoroacetic acid-water (30:70:0.5:0.2, v/v/v/v). Flow rate: $0.5 \mathrm{~mL} / \mathrm{min}$. Detection: $210 \mathrm{~nm}$ UV. Temperature: $20{ }^{\circ} \mathrm{C} . k_{1}$ : Retention factor of the first eluted enantiomer. In the parenthesis, the absolute configuration of the first eluted enantiomer is presented. $\alpha$ : Separation factor. $\mathrm{R}_{\mathrm{S}}$ : Resolution factor. 

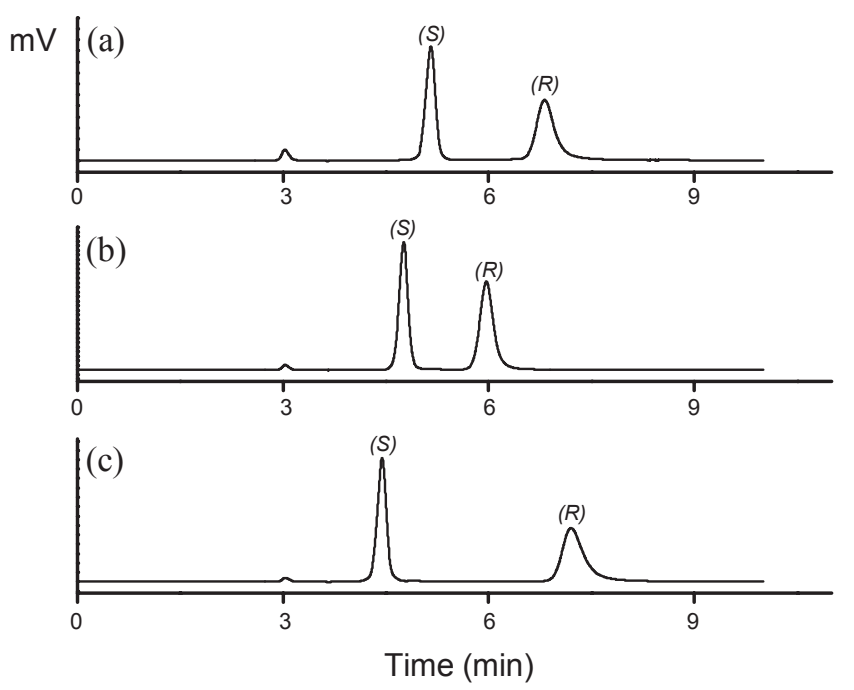

Figure 2. Chromatograms for the resolution of racemic (a) phenylglycine methyl ester (3p), (b) phenylglycine $N, N$-diethylamide (3q) and (c) phenylglycine $N$-propylamide (3r) on $(R, S, S)$-CSP 2 . For the chromatographic conditions, see the footnote to Table 1.

mobile phase are summarized in Table 1. Trifluoroacetic acid in the mobile phase is believed to be used as an acidic modifier to protonate the primary amino group of analytes. Complexation of the resulting ammonium ions $\left(\mathrm{R}-\mathrm{NH}_{3}{ }^{+}\right)$of analytes inside the crown ether ring cavity of the CSPs have been known to be essential for the chiral recognition of primary amino compounds. ${ }^{1,4,6}$ Small amount of water added to the mobile phase is used in order to reduce the peak tailing stemmed from the strong hydrogen bonding between the chiral crown ether moiety of the $\mathrm{CSP}$ and the ionic analytes as proposed previously for the resolution of tocainide and its analogues on $(R, R, R)$-CSP 2 and $(R, S, S)$-CSP 2. ${ }^{9}$

As shown in Table 1, $\alpha$-amino esters and $\alpha$-amino amides (3) were not resolved at all on $(R, R, R)$-CSP 2 . In contrast, $\alpha$-amino methyl eaters were resolved quite well on $(R, S, S)$-CSP 2 except for valine methyl ester (3d) and all of $\alpha$-amino $N$-propylamides were resolved very well with the resolutions $\left(\mathrm{R}_{\mathrm{S}}\right)$ of greater than 1.17. Some of $\alpha$-amino $N, N$-diethylamides were also resolved on $(R, S, S)$-CSP 2. From these results it is concluded that combination of $(R)$-3,3'-diphenyl-1,1'-binaphthyl and $(S, S)$-tartaric acid unit shows a "matched" effect on the chiral recognition while combination of $(R)$-3,3'-diphenyl-1,1'-binaphthyl and $(R, R)$ tartaric acid unit shows a "mismatched" effect as proposed previously for the resolution of tocainide and its analogues on $(R, R, R)$-CSP 2 and $(R, S, S)$-CSP 2. ${ }^{9}$ The results summarized in Table 1 clearly demonstrate that "matched/mismatched" concept, which was first used by Masamune for the double asymmetric induction, ${ }^{10}$ might be applicable to evaluate the chiral recognition ability of the two diastereomeric CSPs consisting of two different chiral units.

Even though the reason for the "matched/mismatched" effect of the two diastereomeric CSPs on the chiral recognition is not clear yet, the two phenyl and the two carboxylic groups of $(R, R, R)$-1 were previously proposed to block the crown ether ring cavity and consequently, the approach of analytes to the crown ether ring cavity and the enantioselective complexation of primary ammonium ions $\left(\mathrm{R}_{-} \mathrm{NH}_{3}{ }^{+}\right)$inside the crown ether ring cavity are quite difficult based on three dimensional structure of $(R, R, R)$-1 obtained with the molecular mechanics calculation (Cache Version 3.2). ${ }^{9}$ On the contrary, the two phenyl and the two carboxylic groups of $(R, S, S)$-1 were proposed to be located relatively outside the crown ether ring cavity and consequently, the approach of analytes to the crown ether ring cavity and the enantioselective complexation of the primary ammonium ions $\left(\mathrm{R}_{-}-\mathrm{NH}_{3}{ }^{+}\right)$of analytes inside the crown ether ring cavity are relatively easy. ${ }^{9}$ In this instance, $(R, S, S)$-CSP 2 derived from $(R, S, S)-\mathbf{1}$ is expected to show higher chiral recognition ability than $(R, R, R)$-CSP 2.

The difference in the chiral recognition efficiency of $(R, S, S)$ CSP 2 for the resolution of $\alpha$-amino methyl esters, $\alpha$-amino $N, N$ diethylamides and $\alpha$-amino $N$-propylamides is quite clear from Table 1. As an example, the different chiral recognition efficiency of $(R, S, S)$-CSP 2 for the resolution of phenylglycine methyl ester (3p), phenylglyicine $N, N$-diethylamide (3q) and phenylglycine $N$-propylamide (3r) are illustrated in Figure 2. Among the three different type derivatives of $\alpha$-amino acids, $\alpha$-amino $N$-propylamides are resolved most efficiently on $(R, S, S)$-CSP 2 in terms of both the separation factors $(\alpha)$ and the resolutions $\left(\mathrm{R}_{\mathrm{S}}\right)$ as shown in Table 1 and Figure 2 . In addition to the complexation of the primary ammonium ion $\left(\mathrm{R}_{-}-\mathrm{NH}_{3}{ }^{+}\right)$in the cavity of the crown ether ring of the CSP, the enantioselective hydrogen bonding between the N-H hydrogen of analytes and the crown ether moiety of the CSP might be responsible for the efficient resolution of $\alpha$-amino $N$-propylamides. However, the exact mode of the hydrogen bonding is not clear yet.

Even though the separation factors $(\alpha)$ for the resolution of $\alpha$-amino methyl esters, $\alpha$-amino $N, N$-diethylamides and $\alpha$-amino $N$-propylamides are always greater on $(R, S, S)$-CSP 2 than on $(R, R, R)$-CSP 2 , the retention times of analytes denoted by the retention factors, $k_{1}$, are always much longer on $(R, R, R)$-CSP 2 than on $(R, S, S)$-CSP 2 under an identical condition as shown in Table 1. The "mismatched" fair of the two different chiral units composing $(R, R, R)$-CSP 2 might retain the two enantiomers strongly and non-enantioselectively instead of the enantioselective complexation of the primary ammonium ions $\left(\mathrm{R}_{-}-\mathrm{NH}_{3}{ }^{+}\right)$of analytes inside the crown ether ring cavity of the CSP. However, the exact reason is not clear yet.

In summary, $(R, S, S)$-CSP 2 incorporating $(R)$-3,3'-diphenyl1,1 '-binaphtyl and $(S, S)$-tartaric acid unit as chiral barriers was found to show quite effective chiral recognition efficiency for the resolution of $\alpha$-amino methyl esters, $\alpha$-amino $N, N$-diethylamides and $\alpha$-amino $N$-propylamides while $(R, R, R)$-CSP 2 incorporating $(R)$-3,3'-diphenyl-1,1'-binaphtyl and $(R, R)$-tartaric acid unit did not show any chiral recognition. From these results it was concluded that the two chiral units composing $(R, S, S)$-CSP 2 show "matched" effect, but those composing $(R, R, R)$-CSP 2 show "mismatched" effect on the chiral recognition. This study provides a good example for the demonstration of the "matched/mismatched" effect of the two different chiral units composing two diastereomeric CSPs. Consequently, we need some efforts to select the "matched" pair of two chiral units in developing effective diastereomeric CSPs. 
Acknowledgments. This research was supported by NCRC (National Core Research Center) program through the National Research Foundation of Korea funded by the Ministry of Education, Science and Technology (grant number: 2010-0008269).

\section{References}

1. (a) (c) Hyun, M. H. Bull. Kor. Chem. Soc. 2005, 26, 1153. (b) Choi, H. J.; Hyun, M. H. J. Liq. Chromatogr. Rel. Technol. 2007, 30, 853.

2. (a) Sousa, L. R.; Sogah, G. D. Y.; Hoffman, D. H.; Cram, D. J. J. Am. Chem. Soc. 1978, 100, 4569. (b) Sogah, G.D.Y.; Cram, D. J. J. Am. Chem. Soc. 1979, 101, 3035.

3. (a) Shinbo, T.; Yamaguchi, T.; Nishimura, K.; Sugiura, M.; J. Chromatogr. 1987, 405, 145. (b) Shinbo, T.; Yamaguchi, T.; Yanagishita, H.; Kitamoto, D.; Sakaki, K.; Sugiura, M. J. Chromatogr. 1992, 625, 101.

4. (a) Hyun, M. H.; Han, S. C.; Lipshutz, B. H.; Shin, Y.-J.; Welch, C. J. J. Chromatogr. A 2001, 910, 359. (b) Hyun, M. H.; Han, S. C.; Lipshutz, B. H.; Shin, Y.-J.; Welch, C. J. J. Chromatogr. A 2002, 959, 75. (c) Hyun, M. H.; Min, H. J.; Cho, Y. J. J. Chromatogr. A 2003, 996, 233. (d) Hyun, M. H.; Tan, G.; Cho, Y. J. Biomed. Chromatogr. 2005, 19, 208. (e) Hyun, M. H.; Han, S. C.; Choi, H. J.; Kang, B. S.; Ha, H. J. J. Chromatogr. A 2007, 1138, 169. (f) Choi, H. J.; Ha, H. J.; Han, S. C.; Hyun, M. H. Anal. Chim. Acta 2008, 619, 122. (g) Welch, C. J.; Hyun, M. H.; Kubota, T.; Schafer, W.; Bernardoni, F.; Choi, H. J.; Wu, N.; Gong, X.; Lipshutz, B. Chirality 2008, 20, 815 (h) Choi, H. J.; Jin, J. S.; Hyun, M. H. J. Chromatogr. B 2008, 875, 102. (i) Choi, H. J.; Jin, J. S.; Hyun, M. H. Chirality 2009, 21, 11. (j) Choi, H. J.; Cho, H. S.; Han, S. C.; Hyun, M. H. J. Sep. Sci. 2009, 32, 536.
5. Behr, J.-P.; Girodeau, J.-M.; Hayward, R. C.; Lehn, J.-M.; Sauvage, J.-P. Hel. Chim. Acta 1980, 63, 2096.

6. (a) Machida, Y.; Nishi, H.; Nakamura, K.; Nakai, H.; Sato, T. J. Chromatogr. A 1998, 805, 85. (b) Hyun, M. H.; Jin, J. S.; Lee, W. J. Chromatogr. A 1998, 822, 155. (c) Hyun, M. H.; Jin, J. S.; Koo, H. J.; Lee, W. J. Chromatogr. A 1999, 837, 75. (d) Hyun, M. H.; Cho, Y. J.; Kim, J. A.; Jin, J. S. J. Chromatogr. A 2003, 984, 163. (e) Hyun, M. H.; Kim, D. H. Chirality 2004, 16, 294. (f) Hyun, M. H.; Cho, Y. J. J. Sep. Sci. 2005, 28, 31. (g) Hyun, M. H.; Song, Y.; Cho, Y. J.; Kim, D. H. J. Chromatogr. A 2006, 1108, 208. (h) Hyun, M. H.; Choi, H. J.; Kang, B. S.; Tan, G.; Cho, Y. J. Bull. Kor. Chem. Soc. 2006, 27, 1775. (i) Hyun, M. H.; Cho, Y. J.; Song, Y.; Choi, H. J.; Kang, B. S. Chirality 2007, 19, 74. (j) Choi, H. J.; Park, Y. J.; Hyun, M. H. J. Chromatogr. A 2007, 1164, 235. (k) Hyun, M. H.; song, Y.; Cho, Y. J.; Choi, H. J. J. Sep. Sci. 2007, 30, 2539. (1) Hyun, M. H.; Song, Y.; Cho, Y. J.; Choi, H. J. Chirality 2008, 20, 325. (m) Lee, S. J.; Cho, H. S.; Choi, H. J.; Hyun, M. H. J. Chromatogr. A 2008, 1188, 318. (n) Cho, H. S.; Choi, H. J.; Lee, A.; Jin, J. S.; Jeong, E. D.; Hyun, M. H. Bull. Kor. Chem. Soc. 2009, 30, 1903. (o) Cho, H. S.; Choi, H. J.; Hyun, M. H. J. Chromatogr. A 2009, 1216,7446

7. (a) Steffeck, R. J.; Zelechonok, Y.; Gahm, K. H. J. Chromatogr. A 2002, 947, 301. (b) Zhang, D.; Li, F.; Kim, D. H.; Choi, H. J.; Hyun, M. H. J. Chromatogr. A 2005, 1083, 89. (c) Hyun. M. H.; Tan, G.; Xue, J. Y. J. Chromatogr. A 2005, 1097, 188. (d) Tan, G.; Xue, J. Y.; Hyun, M. H. J. Sep. Sci. 2006, 29, 1407.

8. Cho, Y. J.; Choi, H. J.; Hyun, M. H. Bull. Kor. Chem. Soc. 2007, 28, 2531.

9. Cho, Y. J.; Choi, H. J.; Hyun, M. H. J. Chromatogr. A 2008, 1191, 193.

10. Masamune, S.; Choy, W.; Peterson, J. S.; Sita, L. R. Agnew. Chem. Int. Ed. Engl. 1985, 24, 1. 